\title{
Formulation and characterization of solid lipid nanoparticles, nanostructured lipid carriers and nanoemulsion of lornoxicam for transdermal delivery
}

\author{
ÜMIT GÖNÜLLÜ ${ }^{1}$ \\ MELIKE ÜNER ${ }^{1 *}$ \\ GÜLGÜN YENER ${ }^{1}$ \\ ECEM FATMA KARAMAN ${ }^{1}$ \\ ZEYNEP AYDOĞMUŞ² \\ ${ }^{1}$ Istanbul University \\ Faculty of Pharmacy \\ Department of Pharmaceutical \\ Technology, Istanbul, Turkey \\ ${ }^{2}$ Istanbul University \\ Faculty of Pharmacy \\ Department of Analytical Chemistry \\ Istanbul, Turkey
}

Accepted October 23, 2014

\begin{abstract}
Solid lipid nanoparticles (SLN), nanostructured lipid carriers (NLC) and nanoemulsion (NE) of lornoxicam (LRX) were prepared for the treatment of painful and inflammatory conditions of the skin. Compritol ${ }^{\circledR} 888$ ATO, Lanette ${ }^{\circledR}$ $\mathrm{O}$ and oleic acid were used as solid and liquid lipids. SLN, NLC and NE were found physically stable at various temperatures for 6 months. Case I diffusional drug release was detected as the dominant mechanism indicating Fickian drug diffusion from nanoparticles and nanoemulsion. The highest rate of drug penetration through rat skin was obtained with NE followed by NLC, SLN and a gel formulation. Nanoformulations significantly increased drug penetration through rat skin compared to the gel $(p<0.05)$. Thus, SLN, NLC and NE of LRX can be suggested for relieving painful and inflammatory conditions of the skin.

Keywords: lornoxicam, solid lipid nanoparticles, nanostructured lipid carriers, nanoemulsion, transdermal delivery, inflammation
\end{abstract}

Lornoxicam (LRX) (chlortenoxicam: 6-chloro-4-hydroxy-2-methyl- $\mathrm{N}-2$-pyridinyl-2Hthieno[2,3-e]-1,2-thiazine-3-carboxamide 1,1-dioxide) is a non-steroidal anti-inflammatory drug (NSAID) of the enolic acid class of oxicam derivatives, with a $\mathrm{p} K_{\mathrm{a}}$ of 4.7 and $\log P$ of $1.8(1,2)$. It is a highly potent drug compared to other NSAIDs. It is used in a wide range of painful and inflammatory conditions. Its analgesic activity was reported to be comparable to those of opioids. LRX was thought to display its effects by inhibition of cyclooxygenase (COX) isoenzymes and thus to inhibit prostaglandin synthesis from arachidonic acid. Prostaglandins play an important role in mucosal protection of the gastrointestinal (GI) tract by inhibiting gastric acid secretion. Therefore, prostaglandin inhibition usually causes GI problems such as dyspepsia, ulceration and bleeding. Several side effects of LRX in the GI tract have been reported although it has better tolerability compared to other NSAIDs. Its renal and hematological side effects can also occur upon oral administration.

\footnotetext{
* Correspondence; e-mail: melikeuner@yahoo.com
} 
Topical application of NSAIDs can be an alternative route to overcome the GI side effects of NSAIDs, including LRX $(3,4)$.

Nanoparticles based on lipophilic materials like waxes or fats appear to be attractive colloidal carrier systems for the delivery of drugs through distinct routes, including topical application $(5,6)$. They have several advantages over traditional delivery systems. Solid lipid nanoparticles (SLN) and nanostructured lipid carriers (NLC) display their unique benefits in drug delivery and various desirable effects on the skin. They have a moisturizing effect on the skin through occlusion providing an increase in skin hydration (7). They are well suited for use on damaged or inflamed skin since they are based on non-irritant and non-toxic lipids. Several studies report successful incorporation of active compounds into SLN and NLC, and their related benefits as colloidal carrier systems are described in the literature (8-11). Nanoemulsion (NE) is also a good candidate for skin delivery of drugs.

Both placebo and LRX-loaded SLN/NLC/NE formulations were attempted to be produced by the hot high pressure homogenization technique. Physical stability experiments on formulations were carried out. Drug penetration through full-thickness skins of rats was studied. A LRX gel was also prepared for comparison with SLN, NLC and NE in in vitro and ex vivo experiments.

\section{EXPERIMENTAL}

\section{Materials}

Lornoxicam was gratefully obtained from Abdi İbrahim İlaç Sanayi ve Tic. A.Ş. (Turkey). Compritol ${ }^{\circledR} 888$ ATO and Lanette ${ }^{\circledR}$ O were kindly provided by B'IOTA Laboratories (Turkey). Pluronic ${ }^{\circledR}$ F68 and oleic acid were purchased from Sigma-Aldrich (Turkey) and Merck (Germany), respectively. Xanthan gum (Inner Mongolia Jianlong Biochemical Co., Ltd, China) was obtained as a gift. All other chemicals were of analytical grade.

\section{Preparation of SLN, NLC and NE}

Placebo SLN formulations (PSLN1 and PSLN2) were prepared by the high pressure homogenization technique at $90{ }^{\circ} \mathrm{C}$ (Table I) (12). Hot aqueous surfactant solution was poured into melted lipid and stirred with an UltraTurrax (IKA, Germany) at 20,000 rpm for 1 minute. The coarse emulsion obtained was homogenized using a double-stage APV2000 high pressure homogenizer (SPX Flow Technology, Poland) at $5 \times 10^{6}$ and $15 \times 10^{7} \mathrm{~Pa}$ for the first and second stage, respectively. Three homogenization cycles were employed. Hot pre-emulsion was poured into silanized transparent vials and sealed. Vials were immediately cooled down to $25^{\circ} \mathrm{C}$ for formation of nanoparticles. LRX was incorporated into the lipophilic phase for preparation of SLN1 and SLN2.

Placebo NLC (PNLC1 and PNLC2) and LRX loaded - NLC formulations (NLC1 and NLC2) were prepared by the same technique under the same conditions. Oleic acid was used by reducing the fraction of $\mathrm{Compritol}^{\circledR} 888$ ATO and Lanette ${ }^{\circledR} \mathrm{O}$ to produce PNLC1 and PNLC2, respectively (i.e. the total lipid content remained unchanged) as can be seen in Table I. $2 \%$ LRX of the total formulation was added by reducing the solid lipid amount in the production of NLC1 and NLC2. 
Ü. Gönüllü et al.: Formulation and characterization of solid lipid nanoparticles, nanostructured lipid carriers and nanoemulsion of lornoxicam for transdermal delivery, Acta Pharm. 65 (2015) 1-13.

Table I. Composition of SLN, NLC and NE formulations

\begin{tabular}{|c|c|c|c|c|c|c|c|c|c|}
\hline \multirow{2}{*}{\multicolumn{2}{|c|}{ Formulations }} & \multicolumn{8}{|c|}{ Composition $(\%, m / m)$} \\
\hline & & LRX & $\begin{array}{c}\text { Compritol }^{\circledR} \\
888 \text { ATO }\end{array}$ & $\begin{array}{c}\text { Lanette }^{\circledR} \\
\mathrm{O}\end{array}$ & $\begin{array}{l}\text { Oleic } \\
\text { acid }\end{array}$ & $\begin{array}{c}\text { Pluronic }^{\circledR} \\
\text { F68 }\end{array}$ & $\begin{array}{l}\text { Xanthan } \\
\text { gum }\end{array}$ & $\begin{array}{c}\text { Propylene } \\
\text { glycol }\end{array}$ & $\begin{array}{l}\text { Bidistilled } \\
\text { water }\end{array}$ \\
\hline \multirow{5}{*}{ Placebo } & PSLN1 & - & 17.5 & - & - & 3 & - & - & 79.5 \\
\hline & PSLN2 & - & - & 17.5 & - & 3 & - & - & 79.5 \\
\hline & PNLC1 & - & 12.0 & - & 5.5 & 3 & - & - & 79.5 \\
\hline & PNLC2 & - & - & 12.0 & 5.5 & 3 & - & - & 79.5 \\
\hline & PNE & - & - & - & 17.5 & 3 & - & - & 79.5 \\
\hline \multirow{6}{*}{$\begin{array}{l}\text { Drug } \\
\text { loaded }\end{array}$} & SLN1 & 2 & 15.5 & - & - & 3 & - & - & 79.5 \\
\hline & SLN2 & 2 & - & 15.5 & - & 3 & - & - & 79.5 \\
\hline & NLC1 & 2 & 10.5 & - & 5.0 & 3 & - & - & 79.5 \\
\hline & NLC2 & 2 & - & 10.5 & 5.0 & 3 & - & - & 79.5 \\
\hline & $\mathrm{NE}$ & 2 & - & - & 15.5 & 3 & - & - & 79.5 \\
\hline & Gel & 2 & - & - & - & - & 2 & 7.5 & 88.5 \\
\hline
\end{tabular}

Placebo and LRX loaded NE (PNE and NE) were produced by completely replacing the solid lipid in SLN formulations with oleic acid using the same production process for comparison (Table I). All vials were then stored at 4, 25 and $40{ }^{\circ} \mathrm{C}$ in the dark in order to determine their physical stability over 6 months.

A LRX gel, as a traditional topical dosage form, was also prepared to evaluate the drug release characteristics and skin penetration behaviour of SLN, NLC and NE through the skin by comparison. For this purpose, xanthan gum was added to the total water content of the gel formulation (Table I). The mixture was kept overnight at $25^{\circ} \mathrm{C}$. LRX was dissolved in propylene glycol and added to the gel using a WiseStir HS-100D propeller stirrer (Daihan Scientific Co Ltd, Korea) at $50 \mathrm{rpm}$ for 15 minutes.

\section{Solubility study}

Phosphate buffer solution (PBS) was used as a receptor phase in in vitro and ex vivo experiments (4). Solubility of LRX was studied in $\mathrm{pH}$ 7.4. Fifteen $\mathrm{mL}$ of $\mathrm{pH} 7.4$ PBS was placed in four 25-mL flasks. A quantity of LRX was placed in each flask, which was greater than the quantity expected to dissolve in the receptor phase. Flasks were tightly closed. All flasks were placed in a water bath (WiseBath ${ }^{\circledR}$, DAIHAN Scientific Co. Ltd.) at $25 \pm 1{ }^{\circ} \mathrm{C}$. Apparatus was maintained under $200 \mathrm{rpm}$ continuous agitation for $24 \mathrm{~h}$. Dispersion was then filtered through $S \& S^{5893}$ blue ribbon filter paper (Schleicher und Schüll, Germany). A measured portion of clear supernatant was removed and diluted. Solubility of LRX in the receptor phase was analysed at $376 \mathrm{~nm}$ (Shimadzu UV-1601 spectrophotometer, Japan).

\section{Entrapment efficiency (EE) and loading capacity (LC) of nanoparticles}

$\mathrm{EE}$ and LC of nanoparticles were determined by analysing the concentration of free drug in dispersion medium $(13,14)$. Nanoparticle dispersion was diluted with water at 
predetermined times. It was centrifuged at 11,148 $\times g$ (Heraeus Biofuge Primo R Centrifuge, Thermo Fisher Scientific, Germany) for $40 \mathrm{~min}$. Proper volume of the supernatant was taken and diluted to $10 \mathrm{~mL}$ with $\mathrm{pH}$ 7.4 PBS. The solution was analysed spectrophotometrically at $376 \mathrm{~nm}$.

\section{FTIR analysis}

FTIR was used to determinate chemical interaction between LRX and other ingredients used in formulations (15). For this purpose, nanoparticle dispersions (NLC1 and NLC2) were diluted with water at predetermined times. Dilutions were centrifuged at $11,148 \times g$ for $40 \mathrm{~min}$. Residues were separetely transferred to glass plates and kept at $50{ }^{\circ} \mathrm{C}$ overnight to eliminate the aqueous phase. Samples were then used for FTIR analysis.

Pure LRX and samples in the powder form were scanned over a wavenumber range of 4000 to $650 \mathrm{~cm}^{-1}$ at a resolution of $4 \mathrm{~cm}^{-1}$ in a Perkin Elmer 100 FTIR instrument (USA) equipped with the Perkin Elmer Spectrum Version 6.0.2 Software. Sample was placed on the sample stage and always the same force (force gauge $100 \mathrm{~N}$ ) was applied to ensure reproducible contact between the sample and crystal for scanning. The system was operating in the transmission mode.

\section{DSC analysis}

DSC was used to obtain information about the melting and crystallization behaviour of solid lipids in nanoparticles, polymorphism, crystal ordering and drug-lipid interactions (16). This was carried out on pure drugs, pure lipids and nanoparticles (Table I). Twenty- $\mu \mathrm{L}$ samples equal to 3-4 mg solid content were weighed into standard sealed aluminium pans (DSC 204 F1 Phoenix ${ }^{\circledR}$, Netzsch, Germany) and heated from 20 to $90{ }^{\circ} \mathrm{C}$ at a heating rate of $10 \mathrm{~K} \mathrm{~min}^{-1}$ flushing with $20 \mathrm{~mL} \mathrm{~N}_{2} \mathrm{~min}^{-1}$. Melting peaks and enthalpies were calculated using the DSC 204 F1 software. Crystalline state of the drug in formulations was demonstrated by calculating the crystallization index (CI, \%) using the following equation (17):

$$
\mathrm{CI}=\frac{M_{\mathrm{s}}}{M_{\mathrm{p}} \gamma} 100
$$

where $M_{\mathrm{s}}$ and $M_{\mathrm{p}}$ are melting enthalpy in $\mathrm{J} \mathrm{g}^{-1}$ of lipid nanoparticles and pure solid lipid, respectively. $\gamma$ represents solid lipid concentration (\%) in nanoparticle dispersion.

\section{Particle and droplet size measurements}

Particle and droplet size distribution of placebo and drug loaded nanoparticles and NE was determined using a Mastersizer 2000 laser diffractometer (LD) equipped with a Hydro 2000MU wet sample dispersion unit (Malvern Instruments Ltd, UK) $(18,19)$. For this purpose, samples were diluted with water at given times and all measurements were performed in triplicate at $25^{\circ} \mathrm{C}$. Water with a refractive index of 1.33 was used as the measurement medium. Results were analysed as the volumetric distribution of particle size. D10, D50 and D90 values (D10, D50 and D90 are maximum particle diameters below which 10,50 and $90 \%$ of the sample volume exists, respectively), and profiles of particle size distribution were obtained. Measurements were performed according to the Mie theory, 
which allows transformation of the measured intensity distribution data to volume in particle size measurements by LD. Each value was the average of three measurements.

\section{In vitro drug release}

The amount of LRX released from formulations was determined using the dialysis bag diffusion technique $(13,20)$. Dialysis bags (Spectra/Por ${ }^{\circledR}$ Dialysis Membrane, MWCO: 3.500, Spectrum Laboratories Inc., USA) were kept in pH 7.4 PBS overnight before the experiment. Bags were filled with $0.5 \mathrm{~g}$ of the formulation and both ends were tightly tied. They were immersed into conical flasks containing $200 \mathrm{~mL}$ pH 7.4 PBS each. Flasks were planted in a water bath adjusted to a constant temperature of $37 \pm 0.5^{\circ} \mathrm{C}$. Experiments were carried out at a 60-rpm continuous agitation for 48 hours. Samples were taken at predetermined time intervals. Sink condition was provided. Drug release was determined spectrophotometrically at $376 \mathrm{~nm}$ after proper dilution of samples. Cumulative amount of LRX in the release medium was plotted as a function of time. Six replicates were conducted for each experiment.

Kinetic evaluation of release profiles was made using zero-order, first-order and Higuchi square-root models, as described in Eqs. (2-4), respectively. Korsmeyer-Peppas equation was also taken into consideration for determination of the release mechanism (Eq. 5) $(21,22)$.

$$
\begin{gathered}
M_{\mathrm{t}}=M_{0}+k_{0} t \\
M_{\mathrm{t}}=M_{\infty}\left(1-\mathrm{e}^{-k_{1} t}\right) \\
M_{\mathrm{t}}=M_{\infty}+k_{\mathrm{H}} t^{1 / 2} \\
M_{\mathrm{t}} / M_{\infty}=K t^{n}
\end{gathered}
$$

where $M_{t}$ and $M_{0}$ are amounts of drug released in the release medium at time $t$ and at $t=$ 0 , respectively, $k_{0}, k_{1}$ and $k_{\mathrm{H}}$ are release constants of the zero-order, first-order and Higuchi square-root model, respectively, $M_{\mathrm{t}} / M_{\infty}$ fractional release of the drug, $k$ and $n$, kinetic constant and diffusional release exponent are indicative of the release mechanism.

\section{HPLC analysis}

Quantification of LRX was performed on a Thermo Separation Products (USA) HPLC unit (controller SN 4000, pump P 4000, autosampler AS 3000, photodiode array detector UV $6000 \mathrm{LP}$ ). UV absorption of LRX in each sample was detected at $384 \mathrm{~nm}$. Data acquisition was performed with the ChromQuest 5.0 software. Separations were provided using a Phenomenex $\mathrm{C}_{18}$-column ( $250 \mathrm{~mm} \times 4.6 \mathrm{~mm}$ i.d., 5 - $\mu \mathrm{m}$ particle size) with a guard column (4 $\mathrm{mm} \times 3 \mathrm{~mm}$ i.d.) packed with the same material.

The isocratic mobile phase was a 60:40 (V/V) mixture of acetonitrile and potassium dihydrogen phosphate buffer $\left(0.05 \mathrm{~mol} \mathrm{~L}^{-1}\right)$ at a flow rate of $1 \mathrm{~mL} \mathrm{~min}^{-1}$. The assays were performed at RT and the injection volume was $20 \mu \mathrm{L}$. 
Stock standard solution of LRX was prepared in the concentration of $0.1 \mathrm{mg} \mathrm{mL}^{-1} \mathrm{us}-$ ing $\mathrm{pH}$ 7.4 PBS as a solvent. Working standard solution of LRX was prepared in the concentration of $10 \mu \mathrm{g} \mathrm{mL}^{-1}$ using the same solvent. To evaluate linearity under the selected conditions, drug determination was carried out at six concentrations in the mobile phase. The calibration curve was found linear over the concentration range of $6.25-500 \mathrm{ng} \mathrm{mL}^{-1}$ $\left(R^{2}=0.9990\right)$. This method was developed and validated for this study. Limit of detection $(L O D)$ and limit of quantification $(L O Q)$ were 0.18 and $0.56 \mathrm{ng} \mathrm{mL}^{-1}$, respectively. For regression equation, relative standard deviations (RSD, \%) of the slope and intercept were 0.1 and 0.2 , respectively.

\section{Drug penetration through excised rat skin}

Eighteen male Wistar albino rats (150-200 g) were provided by DETAE, Istanbul University Institute for Experimental Medicine, Turkey. The animals were housed in plastic cages at constant temperature $\left(22 \pm 1^{\circ} \mathrm{C}\right)$ and humidity $(60 \pm 1 \%)$ under a 12-h light-dark cycle. They were given standard laboratory diet and tap water ad libitum. Rats were acclimatized to the laboratory at least 7 days prior to the experiments. The experimental protocol was approved by the Local Ethical Committee of Animal Experiments in the Experimental Medical Research Institute of Istanbul University, Turkey (2011/33). Rats were sacrificed by cervical dislocation and their skins were depilated. Full-thickness skin of Wistar albino rats were used to evaluate reservoir action potentials of lipid nanoparticles and permeation characteristics of LRX entrapped in lipid nanocarriers through the skin (4, $23,24)$.

The dermal surface was carefully cleaned to remove subcutaneous tissues without damaging the epidermal surface. Underlying fatty tissue was removed by blunt dissection.

One $g$ of the formulation was applied to the donor phase facing the surface of rat skins placed between two halves of Franz-type diffusion cells. Receptor phase was $33.2 \mathrm{~mL} \mathrm{pH}$ 7.4 PBS. The study was performed for 48 hours at $37 \pm 1{ }^{\circ} \mathrm{C}$. Penetration of drugs was assayed by HPLC on samples collected at predetermined time intervals. Three replicates were executed for each experiment.

\section{Analysis of release data}

Statistical evaluations of data obtained from in vitro drug release and ex vivo drug penetration experiments were made by using the one-way ANOVA test in order to determine the differences between profiles. $p<0.05$ was set as the level of significance.

\section{RESULTS AND DISCUSSION}

\section{Solubility of LRX and encapsulation parameters of nanoparticles}

Solubility of LRX in pH 7.4 PBS was $0.303 \pm 0.008 \mathrm{mg} \mathrm{mL}^{-1}$. LRX was successfuly loaded into SLN and NLC based on Compritol ${ }^{\circledR} 888$ ATO, Lanette ${ }^{\circledR} \mathrm{O}$ and oleic acid (Table II). EE and LC were increased by addition of liquid lipid into the lipid phase, providing a more suitable medium for LRX to dissolve during the hot homogenization process, since drugs solubility is usually higher in liquid lipids compared to solid lipids. Liquid lipid also 
Ü. Gönüllü et al.: Formulation and characterization of solid lipid nanoparticles, nanostructured lipid carriers and nanoemulsion of lornoxicam for transdermal delivery, Acta Pharm. 65 (2015) 1-13.

Table II. Entrapment efficiency and loading capacity of nanoparticles

\begin{tabular}{ccc}
\hline Formulations & EE $(\%)^{\mathrm{a}}$ & LC $(\%)^{\mathrm{a}}$ \\
\hline SLN1 & $93.71 \pm 0.25$ & $10.67 \pm 0.01$ \\
SLN2 & $97.22 \pm 0.96$ & $11.10 \pm 0.02$ \\
NLC1 & $94.92 \pm 0.23$ & $10.85 \pm 0.02$ \\
NLC2 & $97.89 \pm 0.25$ & $11.22 \pm 0.02$ \\
\hline
\end{tabular}

EE - entrapment efficieny

LC - loading capacity

${ }^{\mathrm{a}}$ Mean $\pm \mathrm{SD}, n=3$.

influences the crystallization behavior and crystal structure of solid lipid, i.e., it provides a special structure for better drug accommodation in the nanoparticle (5). Crystallization of solid lipid in nanoparticles to its more stable state is prevented. Or, large distances between fatty acid chains and amorphous clusters occur in the nanoparticle structure. Thus, drug accommodation is provided in the structure of nanoparticles in the amorphous state, or containing amorphous clusters.

\section{FTIR analysis}

We extensively discussed the FTIR data of LRX in our previous report (4). FTIR analysis indicated that drug and excipients were compatible at 4, 25 and $40^{\circ} \mathrm{C}$ for 6 months (Fig. 1).

Characteristic main bands of LRX displayed lower intensity and broader peaks caused by other ingredients. $\mathrm{C}=\mathrm{O}$ stretching bands caused by the aliphatic ester structure of triglycerides displayed sharp peaks at $1736.05-1710.54 \mathrm{~cm}^{-1}$. Additional C-H and O-H stretching bands of triglycerydes to those of LRX were detected at $3269.71-2848.36 \mathrm{~cm}^{-1}$.
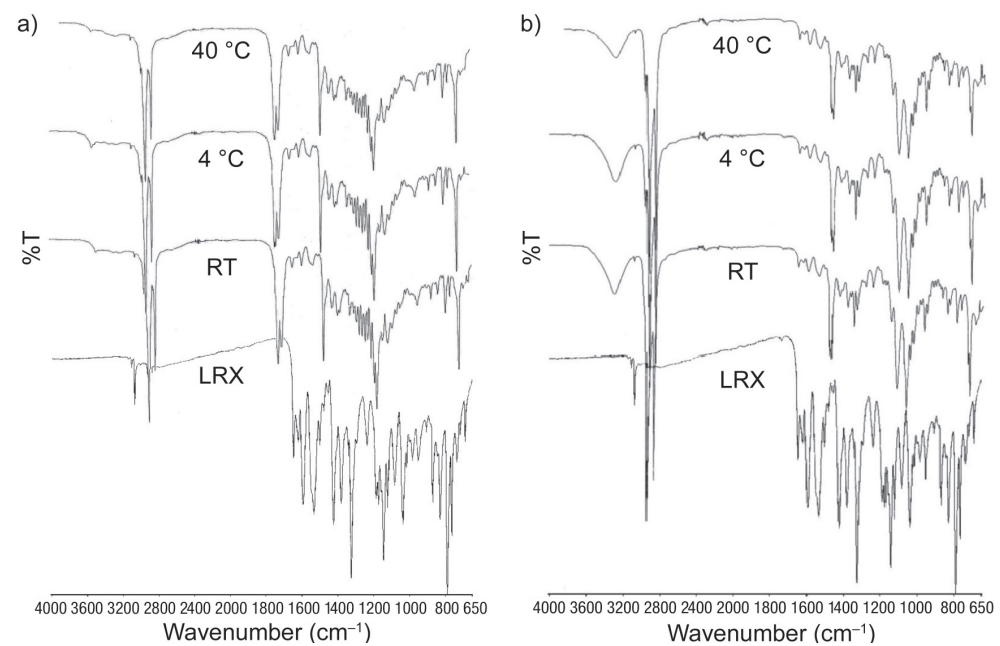

Fig. 1. FTIR spectra of pure LRX, and formulations: a) NLC1 and b) NLC2, stored at 4,25 and $40^{\circ} \mathrm{C}$ for 6 months. 


\section{DSC analysis}

Melting point of pure Compritol ${ }^{\circledR} 888$ ATO was detected at $75.90{ }^{\circ} \mathrm{C}$ with $125.89 \mathrm{~J} \mathrm{~g}^{-1}$ melting enthalpy (Fig. 2). Placebo Compritol ${ }^{\circledR} 888$ ATO nanoparticles PSLN1 gave a broader melting peak at $74.29^{\circ} \mathrm{C}$ with melting enthalpy of $15.45 \mathrm{~J} \mathrm{~g}^{-1}$ due to the addition of surfactant to the dispersion (25). CI was calculated as $70.1 \%$. Decrease in the onset and peak temperatures obtained from nanoparticles could also be attributed to the small size effect, explained by the Thomson equation (17). Increased melting range compared to bulk lipids could be correlated with less ordered crystals or amorphous state. In this case, the melt of the substance requires less energy than a perfect crystalline substance, which needs to overcome the lattice force. It was thus concluded that lower melting enthalpy values compared to bulk solid lipids resulted in a lower ordered lattice arrangement and vice versa. Much less ordered arrangement in NLC formulations was attributed to the existence of liquid lipid as a quest substance. Liquid lipid incorporation resulted in delayed crystallization of nanoparticles. $14.43 \mathrm{~J} \mathrm{~g}^{-1}\left(72.48^{\circ} \mathrm{C}\right)$ and $12.17 \mathrm{~J} \mathrm{~g}^{-1}\left(71.97^{\circ} \mathrm{C}\right)$ melting enthalpies were obtained from placebo (PNLC1) and drug loaded nanoparticles (NLC1), resulting in 67.3 and $59.8 \% \mathrm{CI}$, respectively.
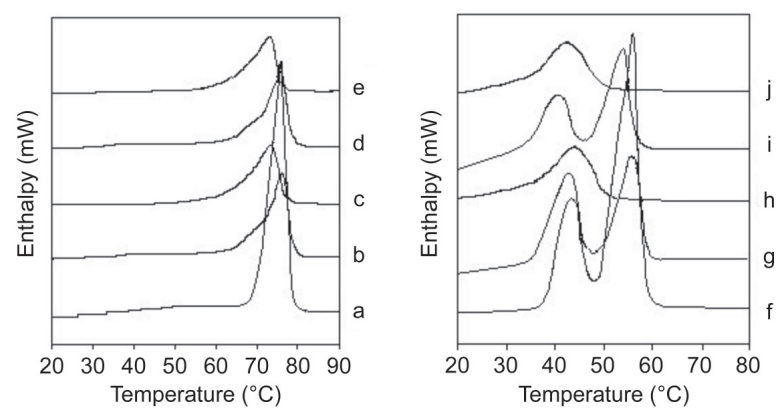

Fig. 2. DSC curves of pure solid lipids and nanoparticles: a) pure Compritol ${ }^{\circledR} 888$ ATO, b) PSLN1, c) PNLC1, d) SLN1, e) NLC1, g) PSLN2, h) PNLC2, i) SLN2 and j) NLC2.

Incorporation of drug in SLN1 depressed the melting point and melting enthalpy to $73.11^{\circ} \mathrm{C}$ and $15.19 \mathrm{~J} \mathrm{~g}^{-1}$, respectively, resulting in $69.0 \% \mathrm{CI}$. After 6 months of storage, 69.3 and $60.2 \%$ CI were obtained for SLN1 and NLC1 at $25{ }^{\circ} \mathrm{C}$, respectively. Storage temperature significantly affected the crystallization behaviour of nanoparticles. Increase in storage temperature resulted in delay of the crystallization process of the lipid. Moreover, 40 ${ }^{\circ} \mathrm{C}$ temperature downgraded $\mathrm{CI}$ due to spoiling of the crystal structure of nanoparticles. $\mathrm{CI}$ values obtained from SLN1 stored at 4 and $40{ }^{\circ} \mathrm{C}$ for 6 months were 72.5 and $62.7 \%$ while those of NLC1 were 62.0 and $55.0 \%$, respectively.

Lanette ${ }^{\circledR} \mathrm{O}$ gave a double peak at 43.26 and $55.95^{\circ} \mathrm{C}$, which could be attributed to the mixture of cetyl alcohol and stearyl alcohol (Fig. 2). In placebo SLN (PSLN2), peaks were broader and showed a tendency to be shifted by the second peak in the case of drug incorporation (SLN2). NLC formulations (PNLC2 and NLC2) gave broader peaks. After 6 months of storage, the crystallization behavior of nanoparticles based on Lanette ${ }^{\circledR} \mathrm{O}$ was slightly altered at $25{ }^{\circ} \mathrm{C}$ compared to the DSC curves obtained before storage (thermograms obtained for the formulation after storage are not shown). 
Ü. Gönüllü et al.: Formulation and characterization of solid lipid nanoparticles, nanostructured lipid carriers and nanoemulsion of lornoxicam for transdermal delivery, Acta Pharm. 65 (2015) 1-13.

\section{Particle and droplet size of nanoparticles and NE}

LD analysis displayed narrow size distributions for nanoparticles and NEs (Table III). Formulations were obtained in a range of 0.141 to $0.295 \mu \mathrm{m}$ diameter (D50). SLN based on Compritol ${ }^{\circledR} 888$ ATO and Lanette ${ }^{\circledR}$ O showed 0.185 and $0.295 \mu \mathrm{m}$ particle size, whereas NLC displayed 0.185 and $0.266 \mu \mathrm{m}$ particle size, respectively. Droplet size of NE was 0.166 $\mu \mathrm{m}$. It was observed that addition of liquid oil into the lipophilic phase resulted in a decrease in particle size while drug incorporation did not cause any significant change. As a consequence, NEs had the lowest droplet size, as expected. Smaller particle and droplet size of NLC and NE formulations compared to SLN formulations can be attributed to the fact that lower viscosity of the lipophilic phase resulted in a decrease in size during the hot homogenization process.

Table III. D10, D50, D90 values obtained from laser diffractometry

\begin{tabular}{|c|c|c|c|c|c|c|}
\hline \multirow[b]{2}{*}{ Formulations } & \multirow{2}{*}{$\begin{array}{l}\text { Storage } \\
\text { conditions }\end{array}$} & \multicolumn{5}{|c|}{ Mean diameter $(\mu \mathrm{m})$} \\
\hline & & D10 & D50 & D90 & $\begin{array}{c}\text { Surface } \\
\text { weighted mean }\end{array}$ & $\begin{array}{c}\text { Volume } \\
\text { weighted mean }\end{array}$ \\
\hline PSLN1 & PD & 0.111 & 0.163 & 0.336 & 0.165 & 0.178 \\
\hline \multirow{4}{*}{ SLN1 } & PD & 0.139 & 0.185 & 0.361 & 0.182 & 0.196 \\
\hline & $4{ }^{\circ} \mathrm{C}$ & 0.153 & 0.199 & 0.381 & 0.197 & 0.212 \\
\hline & $25^{\circ} \mathrm{C}$ & 0.158 & 0.192 & 0.397 & 0.189 & 0.214 \\
\hline & $40^{\circ} \mathrm{C}$ & 0.125 & 0.172 & 0.343 & 0.168 & 0.184 \\
\hline PSLN2 & PD & 0.134 & 0.282 & 0.616 & 0.278 & 0.295 \\
\hline \multirow{4}{*}{ SLN2 } & PD & 0.245 & 0.295 & 0.671 & 0.291 & 0.308 \\
\hline & $4{ }^{\circ} \mathrm{C}$ & 0.259 & 0.314 & 0.771 & 0.310 & 0.316 \\
\hline & $25^{\circ} \mathrm{C}$ & 0.348 & 0.391 & 4.699 & 0.392 & 0.415 \\
\hline & $40^{\circ} \mathrm{C}$ & 0.224 & 0.282 & 0.658 & 0.179 & 0.294 \\
\hline PNLC1 & PD & 0.091 & 0.141 & 0.298 & 0.138 & 0.153 \\
\hline \multirow{4}{*}{ NLC1 } & PD & 0.130 & 0.185 & 0.361 & 0.183 & 0.197 \\
\hline & $4{ }^{\circ} \mathrm{C}$ & 0.129 & 0.172 & 0.262 & 0.170 & 0.183 \\
\hline & $25^{\circ} \mathrm{C}$ & 0.140 & 0.198 & 0.386 & 0.195 & 0.211 \\
\hline & $40^{\circ} \mathrm{C}$ & 0.144 & 0.192 & 0.279 & 0.189 & 0.204 \\
\hline PNLC2 & PD & 0.169 & 0.218 & 0.429 & 0.215 & 0.231 \\
\hline \multirow{4}{*}{ NLC2 } & PD & 0.214 & 0.266 & 0.536 & 0.263 & 0.279 \\
\hline & $4^{\circ} \mathrm{C}$ & 0.203 & 0.261 & 1.491 & 0.261 & 0.275 \\
\hline & $25^{\circ} \mathrm{C}$ & 0.214 & 0.265 & 2.522 & 0.268 & 0.281 \\
\hline & $40^{\circ} \mathrm{C}$ & 0.152 & 0.206 & 0.411 & 0.203 & 0.218 \\
\hline PNE & PD & 0.122 & 0.189 & 0.417 & 0.177 & 0.201 \\
\hline \multirow{4}{*}{ NE } & PD & 0.121 & 0.166 & 0.355 & 0.163 & 0.178 \\
\hline & $4{ }^{\circ} \mathrm{C}$ & 0.149 & 0.195 & 0.436 & 0.193 & 0.208 \\
\hline & $25^{\circ} \mathrm{C}$ & 0.161 & 0.205 & 0.464 & 0.203 & 0.217 \\
\hline & $40^{\circ} \mathrm{C}$ & 0.127 & 0.168 & 0.408 & 0.165 & 0.172 \\
\hline
\end{tabular}

Values from particle and droplet size measurements of formulations at production date (PD) and after storage at 4 , 25 and $40{ }^{\circ} \mathrm{C}$ for 6 months. 
In general, particle size of SLN1 and NLC1 based on Compritol ${ }^{\circledR} 888$ ATO did not significantly alter at various temperatures over 6 months, indicating good physical stability. However, SLN2 and NLC2 based on Lanette ${ }^{\circledR} \mathrm{O}$ displayed slight agglomeration after 6 months. Droplet size of NE ranged between 0.168 and $0.205 \mu \mathrm{m}$ under all conditions during 6 months.

\section{In vitro drug release}

Controlled drug release was observed for all nanoformulations. LRX gel gave the fastest drug release: $100 \%$ for 24 hours ( $p<0.05$ ), followed by 97.7, 73.7, 64.2, 54.6 and $49.2 \%$ for NE, NLC2, NLC1, SLN2 and SLN1, respectively, after 48 hours (Fig. 3). NLC formulations displayed higher release rates compared to SLN formulations containing the same solid lipids (SLN1 vs. NLC1, $p<0.05$ and SLN2 vs. NLC2, $p<0.05$ ). Although a non-significant difference was observed between formulations SLN2 and NLC1, the release rate of LRX increased with a decrease in CI and crystalline state of nanoparticles in general. Addition of liquid lipids provided easier drug diffusion. Addition of liquid lipid to SLN based on Lanette ${ }^{\circledR} \mathrm{O}$ (NLC2) revealed more imperfections.

Table IV indicates that drug release from SLN1, SLN2 and NE met the Higuchi and Korsmeyer-Peppas models whereas NLC1 and NLC2 displayed drug release according to the the Korsmeyer-Peppas model. Higuchi matrix kinetics was strictly dominant for LRX release from the gel. Release exponent of the Korsmeyer-Peppas model $(n)$ was obtained to characterize the drug release mechanism from nanoparticles and Fickian diffusion release (case I diffusional) was determined $(0.5<n)(21,22)$. Case I diffusional transport was thought to be valid here, indicating basic drug diffusion from nanoparticles and NE. The release medium did not enter into nanoparticles and drug release was independent of water penetration into the matrix (26). It was concluded that data obtained from the in vitro release study explained the solid solution model of LRX encapsulation of SLN1 and SLN2. 29.76 and $31.29 \%$ of the drug were released from nanoparticles and drug release reached 49.21 and $54.59 \%$ after 48 hours, respectively. Burst release of the drug was controversial here. Korsmeyer-Peppas calculation also indicated the Higuchi square-root model drug release, giving the highest $R$ values among zero-order and first-order drug release models. NLC1 and NLC2 were thought to contribute to amorphous or imperfect types of the drug encapsulation model under consideration of the in vitro release study and kinetic evaluation. Thermal behaviours of nanoparticles displayed by DSC experiments supported our thesis.

Table IV. Kinetic evaluation of drug release from formulations

\begin{tabular}{lcccc}
\hline Formulations & $\begin{array}{c}\text { Zero-order } \\
R\end{array}$ & $\begin{array}{c}\text { First-order } \\
R\end{array}$ & $\begin{array}{c}\text { Higuchi model } \\
R\end{array}$ & $\begin{array}{c}\text { Korsmeyer-Peppas } \\
\text { model, } R(n)\end{array}$ \\
\hline SLN1 & 0.9151 & 0.8114 & 0.9923 & $0.9935(0.441)$ \\
SLN2 & 0.9268 & 0.8253 & 0.9905 & $0.9911(0.439)$ \\
NLC1 & 0.9364 & 0.8502 & 0.9829 & $0.9944(0.440)$ \\
NLC2 & 0.9423 & 0.8468 & 0.9843 & $0.9948(0.450)$ \\
NE & 0.9007 & 0.7858 & 0.9896 & $0.9901(0.450)$ \\
Gel & 0.7589 & 0.6638 & 0.9693 & $0.9264(0.376)$ \\
\hline
\end{tabular}

$R$ - correlation coefficient

$n$-diffusion exponent of release profile (slope) 


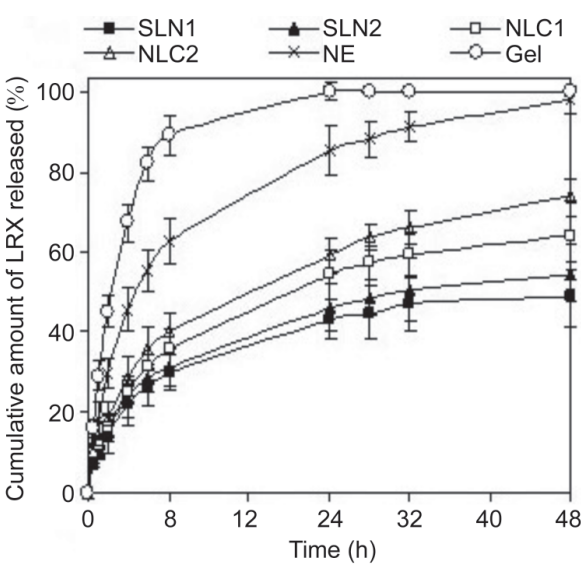

Fig. 3. Release profiles of LRX from nanoparticles and NE in $\mathrm{pH} 7.4$ PBS. Points are mean \pm SD, $n=6$.

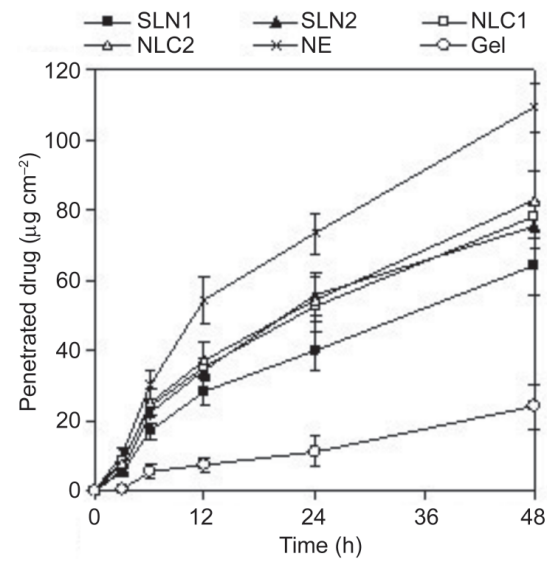

Fig. 4. LRX penetration through full thickness skin of Wistar albino rats from nanoparticles and NE. Points are mean $\pm \mathrm{SD}, n=3$.

\section{Drug penetration through rat skin}

Drug flux across the skin might be an indicator of drug deposition within the skin for transdermal delivery of drugs.

SLN and NLC dispersions were shown to increase the penetration rate compared to LRX gel $(p<0.05)$. The highest release rate was obtained with NE $\left(2.017 \mu \mathrm{g} \mathrm{cm}^{-2} \mathrm{~h}^{-1}\right)$, followed by NLC2 $\left(1.524 \mu \mathrm{g} \mathrm{cm}^{-2} \mathrm{~h}^{-1}\right)$, SLN2 $\left(1.431 \mu \mathrm{g} \mathrm{cm}^{-2} \mathrm{~h}^{-1}\right)$, NLC1 $\left(1.425 \mu \mathrm{g} \mathrm{cm}^{-2} \mathrm{~h}^{-1}\right)$ and SLN1 (1.200 $\left.\mathrm{g} \mathrm{cm}^{-2} \mathrm{~h}^{-1}\right)$ (Fig. 4). However, statistically similar penetration profiles were obtained with SLN2, NLC1 and NLC2. The steady-state flux that drug penetration reached differed for each formulation. It was observed between 6 and 48 hours for SLN1, NLC1 and NLC2, 6 and 24 hours for SLN2, and between 3 and 12 hours for NE. LRX gel displayed a steady-state flux between 6 and 24 hours. In those periods, penetration rates were 1.073, 1.857, 1.262, 1.342, 4.746 and $0.326 \mu \mathrm{g} \mathrm{cm}^{-2} \mathrm{~h}^{-1}$ for SLN1, SLN2, NLC1, NLC2, NE and LRX gel, respectively. Liquid lipid composition of droplets and lower droplet size of NE (0.166 $\mu \mathrm{m}, \mathrm{D} 50)$, compared to the particle size of SLN1 $(0.185 \mu \mathrm{m})$ and NLC1 $(0.185 \mu \mathrm{m})$ based on Compritol ${ }^{\circledR} 888$ ATO, and SLN2 $(0.295 \mu \mathrm{m})$ and NLC2 $(0.266 \mu \mathrm{m})$ based on Lanette ${ }^{\circledR}$ O, resulted in the highest LRX penetration rate. Additionally, NE spoiled the lipid organisation in the deeper horny layer and thus increased skin penetration of the drug. In the case of SLN and NLC, spontaneous occlusivity contributed to the penetration properties through the skin due to the particle size of formulations in the nanometer range. Subsequent skin hydration promoted drug penetration $(7,9,27)$. Particle size of SLN and NLC in the nanometer range led to their transfer into deeper skin layers. Nanoparticles then displayed reservoir action and sustained drug release through their pysicochemical properties such as high lipophilicity and solid state at body temperature. As a result, nanoparticles were found to release the drug as a consequence of polymorphic transitions in the solid lipid while penetrating across the skin. 


\section{CONCLUSIONS}

SLN, NLC and NE of LRX were successfuly prepared with a high drug payload using Compritol ${ }^{\circledR} 888$ ATO, Lanette ${ }^{\circledR} \mathrm{O}$ and oleic acid as solid and liquid lipids. Stability experiments displayed that they were physically stable and drug-excipient compatibility was available during 6 months of storage. They increased the skin penetration rate of the drug for 3-4 times compared to a traditional LRX gel formulation, acting as a depot to provide sustained drug release in the skin. As a result, SLN, NLC and NE of LRX were concluded to offer benefits for the treatment of inflammatory and painful conditions via topical application while decreasing side-effects of the drug caused by oral administration.

Acknowledgements. - We thank the Biofarma Pharmaceutical Industry Co. Inc. in Istanbul and Argis Pharmaceutical Research and Development in Ankara for their contributions.

\section{REFERENCES}

1. The Merck Index - An Encyclopedia of Chemicals, Drugs, and Biologicals (Ed. M. J. O'Neil), $14^{\text {th }}$ ed., Merck Publishing Group, Merck \& Co., Inc., Whitehouse Station 2006.

2. D. S. P. Byrav, B. Medhi, A. Prakash, S. Patyar and S. Wadhwa, Lornoxicam: A newer NSAID, Indian J. Phys. Med. Rehabil. 20 (2009) 27-31.

3. F. B. Riecke, E. M. Bartels, S. Torp-Pedersen, S. Ribel-Madsen, H. Bliddal, B. Danneskiold-Samsøe and L. Arendt-Nielsen, A microdialysis study of topically applied diclofenac to healthy humans: Passive versus iontophoretic delivery, Res. Pharm. Sci. 1 (2011) 76-79; DOI: 10.1016/j. rinphs.2011.11.001.

4. G. Yener, M. Üner, Ü. Gönüllü, S. Yıldırım, P. Kılıç, S. Sağlık Aslan and A. Barla, Design of meloxicam and lornoxicam transdermal patches: Preparation, physical characterization, ex vivo and in vivo studies, Chem. Pharm. Bull. 58 (2010) 1466-1473; DOI: 10.1248/cpb.58.1466.

5. M. Üner, Preparation, characterization and physico-chemical properties of solid lipid nanoparticles (SLN) and nanostructured lipid carriers (NLC): Their benefits as colloidal drug carrier systems, Pharmazie 61 (2006) 375-386.

6. M. Üner and G. Yener, Importance of solid lipid nanoparticles (SLN) in various administration routes and future perspectives, Int. J. Nanomed. 2 (2007) 289-300.

7. S. A. Wissing, A. Lippacher and R. H. Müller, Investigations on the occlusive properties of solid lipid nanoparticles (SLN), J. Cosmet. Sci. 52 (2001) 313-324.

8. H. Chen, X. Chang, D. Du, W. Liu, J. Liu, T. Weng, Y. Yang, H. Xu and X. Yang, Podophyllotoxinloaded solid lipid nanoparticles for epidermal targeting, J. Control. Release 110 (2006) 296-306; DOI: 10.1016/j.jconrel.2005.09.052.

9. C. Puglia, P. Blasi, L. Rizza, A. Schoubben, F. Bonina, C. Rossi and M. Ricci, Lipid nanoparticles for prolonged topical delivery: An in vitro and in vivo investigation, Int. J. Pharm. 357 (2008) 295304; DOI: 10.1016/j.ijpharm.2008.01.045.

10. S. Küchler, N. B. Wolf, S. Heilmann, G. Weindl, J. Helfmann, M. M. Yahya, C. Stein and M. SchäferKorting, 3D-wound healing model: influence of morphine and solid lipid nanoparticles, J. Biotechnol. 148 (2010) 24-30; DOI: 10.1016/j.jbiotec.2010.01.001.

11. V. Sanna, G. Caria and A. Mariani, Effect of lipid nanoparticles containing fatty alcohols having different chain length on the ex vivo skin permeability of econazole nitrate, Powder Technol. 201 (2010) 32-36; DOI: 10.1016/j.powtec.2010.02.035. 
12. E. B. Souto, C. Anselmi, M. Centini and R. H. Müller, Preparation and characterization of $n$-dodecyl-ferulate-loaded solid lipid nanoparticles $\left(\mathrm{SLN}^{\circledR}\right)$, Int. J. Pharm. 295 (2005) 261-268; DOI: 10.1016/j.ijpharm.2005.02.005.

13. M. Ghadiri, S. Fatemi, A. Vatanara, D. Doroud, A. R. Najafabadi, M. Darabi and A. A. Rahimi, Loading hydrophilic drug in solid lipid media as nanoparticles: Statistical modeling of entrapment efficiency and particle size, Int. J. Pharm. 424 (2012) 128-137; DOI: 10.1016/j.ijpharm.2011.12.037.

14. Y. C. Kuo and H. H. Chen, Entrapment and release of saquinavir using novel cationic solid lipid nanoparticles, Int. J. Pharm. 365 (2009) 206-213; DOI: 10.1016/j.ijpharm.2008.08.050.

15. O. W. Stott, A. C. Williams and B. W. Barry, Transdermal delivery from eutectic systems: enhanced permeation of a model drug, ibuprofen, J. Control. Release 50 (1998) 297-308; DOI: 10.1016/S01683659(97)00153-3.

16. J. L. Ford and P. Timmins, Pharmaceutical Thermal Analysis, Ellis Horwood, Chichester 1989.

17. B. Siekmann and K. Westesen, Thermoanalysis of the recrystallization process of melt-homogenized glyceride nanoparticles, Colloids Surf., B. Biointerfaces 3 (1994) 159-175; DOI: 10.1016/09277765(94)80063-4.

18. J. Pardeike, S. Webera, T. Haber, J. Wagner, H. P. Zarfl, H. Plank and A. Zimmer, Development of an itraconazole-loaded nanostructured lipid carrier (NLC) formulation for pulmonary application, Int. J. Pharm. 419 (2011) 329-338; DOI: 10.1016/j.ijpharm.2011.07.040.

19. D. Z. Hou, C. S. Xie, K. J. Huang and C. H. Zhu, The production and characteristics of solid-lipid nanoparticles (SLNs), Biomaterials 34 (2003) 1781-1785; DOI: 10.1016/S0142-9612(02)00578-1.

20. S. Das, W. K. Ng and R. B. H. Tan, Are nanostructured lipid carriers (NLCs) better that solid lipid nanoparticles (SLNs): Development, characterizations and comparative evaluations of clotrimazole-loaded SLNs and NLCs?, Eur. J. Pharm. Sci. 47 (2012) 139-151; DOI: 10.1016/j.ejps.2012.05.010.

21. P. Costa and J. M. Sousa Lobo, Modeling and comparison of dissolution profiles, Eur. J. Pharm. Sci. 13 (2001) 123-133; DOI: 10.1016/S0928-0987(01)00095-1.

22. R. W. Korsmeyer, R. Gurney, E. M. Doelker, P. Buri and N. A. Peppas, Mechanism of solute release from porous hydrophilic polymers, Int. J. Pharm. 15 (1983) 25-35. DOI: 10.1016/0378-5173(83)90064-9.

23. J. Y. Fang, C. L. Fang, C. H. Liu and Y. H. Su, Lipid nanoparticles as vehicles for topical psoralen delivery: Solid lipid nanoparticles (SLN) versus nanostructured lipid carriers (NLC), Eur. J. Pharm. Biopharm. 70 (2008) 633-640; DOI: 10.1016/j.ejpb.2008.05.008.

24. M. Joshi and V. Patravale, Nanostructured lipid carrier (NLC) based gel of celecoxib, Int. J. Pharm. 346 (2008) 124-132; DOI: 10.1016/j.ijpharm.2007.05.060.

25. A. Zur Mühlen, C. Schwarz and W. Mehnert, Solid lipid nanoparticles (SLN) for controlled drug delivery - Drug release and release mechanism, Eur. J. Pharm. Biopharm. 45 (1998) 149-155; DOI: 10.1016/S0939-6411(97)00150-1.

26. K. Bhaskar, J. Anbu, V. Ravichandiran, V. Venkatesvarlu and Y. M. Rao, Lipid nanoparticles for transdermal delivery of flurbiprofen: formulation, in vitro, ex vivo and in vivo studies, Lipids Health Dis. 8 (2009) 1-15; DOI: 10.1186/1476-511X-8-6.

27. S. K. Jain, M. K. Chourasia, R. Masuriha, V. Soni, A. Jain, N. K. Jain and Y. Gupta, Solid lipid nanoparticles bearing flurbiprofen for transdermal delivery, Drug Deliv. 12 (2005) 207-215; DOI: 10.1080/10717540590952591. 